\title{
GEOPARK SILOKEK SIJUNJUNG MENUJU UNESCO GLOBAL GEOPARK
}

\author{
SIJUNJUNG SILOKEK GEOPARK TOWARDS UNESCO \\ GLOBAL GEOPARK
}

\author{
Desi Widia Kusuma \\ Badan Penelitian dan Pengembangan Provinsi Sumatera Barat \\ Jl. Jenderal Sudirman No. 51, Padang \\ Email : desiranawk@gmail.com
}

Naskah Masuk: 20-03-2019 Naskah Diterima: 11-05-2019 Naskah Disetujui: 06-06-2019

\begin{abstract}
Silokek Geopark is located in Sijunjung Regency with an area of $\pm 1300 \mathrm{~km}^{2}$. Silokek Geopark has been designated as the National Geopark on 30 November 2018 with 25 geodiversity sites, 12 biodiversity sites and 17 cultural diversity sites. After being designated as the National Geopark, the next hope is to be designated as the UNESCO Global Geopark. Based on this, a study was conducted which aimed to analyze the condition of the Geopark Silokek based on UNESCO Global Geopark criteria and to find out the challenges in the development of Silopek Geopark. The study was conducted in May-August 2018 in Sumpur Kudus District and Sijunjung District. Primary data is obtained from field observations and interviews with relevant agencies, while secondary data is obtained based on searches of technical documents and journals. From the results of the study it is known that several UNESCO criteria that need to be improved and disemployed are the management of Geopark Silokek, aspects of economic development and aspects of education. This improvement can be done by revising the structure of the Silokek Geopark Management Agency, building geotrack lines and supporting facilities, increasing community empowerment and overcoming environmental problems on the Batang Kuantan River.
\end{abstract}

Key words: Silokek Geopark, UNESCO Global Geopark, geotrack

Geopark Silokek terletak di Kabupaten Sijunjung dengan luas kawasan $\pm 1300 \mathrm{~km}^{2}$. Geopark Silokek telah ditetapkan menjadi Geopark Nasional pada tanggal 30 November 2018 dengan 25 situs geodiversity, 12 situs biodiversity dan 17 situs cultural diversity. Setelah ditetapkan sebagai Geopark Nasioanl maka harapan selanjutnya adalah ditetapkan sebagai UNESCO Global Geopark. Berdasarkan hal tersebut maka dilakukan kajian yang bertujuan untuk menganalisis kondisi Geopark Silokek berdasarkan kriteria UNESCO Global Geopark dan mengetahui tantangan dalam pengembangan Geopark Silokek. Kajian dilaksanakan pada Bulan Mei-Agustus 2018 di Kecamatan Sumpur Kudus dan Kecamatan Sijunjung. Data primer diperoleh dari observasi lapangan dan wawancara dengan instansi terkait, sedangkan data sekunder diperoleh berdasarkan penelusuran dokumen teknis dan jurnal. Dari hasil kajian diketahui bahwa beberapa kriteria UNESCO yang perlu diperbaiki dan disempunakan adalah manajemen pengelola Geopark Silokek, aspek pengembagan ekonomi dan aspek pendidikan. Perbaikan ini dapat dilakukan dengan merevisi struktur Badan Pengelola Geopark Silokek, membangun jalur geotrack beserta fasilitas pendukungnya, meningkatkan pemberdayaan masyarakat dan mengatasi permasalahan lingkungan pada Sungai Batang Kuantan.

Kata Kunci: Geopark Silokek, Unesco Global Geopark, geotrack 


\section{PENDAHULUAN}

Kabupaten Sijunjung ditetapkan sebagai Daerah Pelayanan Pariwisata (DPP) V destinasi/tujuan wisata Provinsi Sumatera Barat yang meliputi wisata alam, wisata budaya/sejarah, dan wisata buatan. Sebagai daerah tujuan wisata, Pemerintah Kabupaten Sijunjung terus berupaya untuk memajukan pariwisata daerahnya sehingga membuahkan hasil dengan meningkatnya jumlah kunjungan wisatawan ke Sijunjung. Pada tahun 2016 jumlah wisatawan yang masuk ke Sijunjung sebanyak 9.920 orang (8861 orang wisatawan domestik dan 359 orang wisatawan asing). Pada tahun 2017 terjadi peningkatan menjadi 12.718 orang yang terdiri dari 12.466 orang wisatawan domestik dan 252 orang wisatawan asing. (LAKIP Kabupaten Sijunjung, 2017).

Dalam Keputusan Bupati Sijunjung Nomor: 188.45/338/KPTSBPT-2016 tentang Penetapan Kawasan Wisata Strategis dan Destinasi Pariwisata di Kabupaten Sijunjung, telah ditetapkan 66 objek wisata yang terdiri dari 46 objek wisata alam, 12 objek wisata budaya dan 8 objek wisata minat khusus (LAKIP Dinas Parpora Kab. Sijunjung, 2017).
Dari ke 66 objek wisata yang ada, terdapat beberapa objek wisata yang berpotensi untuk dikembangkan menjadi geopark yang berada di Kecamatan Sijunjung dan Kecamatan Sumpur Kudus dan disebut dengan Geopark Silokek.

Geopark adalah sebuah konsep manajemen pengembangan kawasan berkelanjutan yang menyerasikan keragaman geologi, hayati dan budaya melalui prinsip konservasi dan Rencana Tata Ruang Wilayah yang sudah ada. Geopark merupakan wilayah geografis yang memiliki situs warisan geologi terkemuka dan bagian dari konsep holistik perlindungan, pendidikan dan pembangunan yang berkelanjutan (Dinas Pariwisata dan Kebudayaan Jawa Barat, 2017).

Secara geologi, Silokek sangat menarik karena telah melewati 3 (tiga) era dalam skala waktu geologi yang tercermin dalam susunan batuan yang membentuk kawasan. Batuan tertua di kawasan ini terbentuk pada Era Paleozoikum tepatnya pada Periode Permian (299 - 252 Juta Tahun yang lalu) dan Carboniferous (359-299 Juta Tahun yang lalu). Kondisi morfologi Silokek terlihat berupa tebing karst dengan 
kemiringan landai dan bergelombang berada pada ketinggian 200 sampai 400 meter. Sedangkan daerah dengan ketinggian 500 meter sampai 600 meter merupakan daerah puncak kawasan bukit karst. Punggungan atau bukit-bukit memanjang/elipsoid, berukuran panjang rata-rata 400 - 600 meter dan lebar 100 150 meter. Disamping bukit-bukit karst, daerah ini juga memiliki keanekaragaman hayati dan keragaman budaya yang tinggi (Dossier Silokek, 2018).

Penetapan Silokek sebagai Geopark Nasional ditandai dengan penyerahan sertifikat Geopark Nasional oleh Menteri Pariwisata, Arief Yahya kepada Bupati Sijunjung, Yuswir Arifin di Museum Tambang Antam Kecamatan Nanggung Kabupaten Bogor, Jawab Barat pada tanggal 30 November 2018. Setelah ditetapkan sebagai geopark nasional, maka harapan selanjutnya adalah dapat mendaftar sebagai UNESCO Global Geopark (UGG). Keuntungan yang diperoleh jika menjadi anggota UGG antara lain : 1) terpromosikan secara internasional tanpa biaya besar, 2) menjadi icon baru pariwisata yang berbasis masyarakat dan konservasi sehingga dapat lebih menarik wisatawan mancanegara untuk berkunjung, 3) menjunjung komitmen program pembangunan berkelanjutan sebagaimana yang terdapat dalam Agenda 21 (Tim Geopark Ranah Minang, 2018).

Sampai saat ini, Indonesia telah memiliki 4 (empat) geopark yang sudah terdaftar sebagai UGG yakni : CiletuhPelabuhan Ratu, Rinjani, Gunung Sewu dan Merangin Jambi. Kajian ini bertujuan untuk menganalisis kondisi Geopark Silokek pasca ditetapkan sebagai Geopark Nasional, memberikan rekomendasi teknis dan non teknis dalam memenuhi kriteria UGG dan mengetahui tantangan dalam pengembangan Geopark Silokek.

\section{METODOLOGI}

Kajian dilaksanakan pada Bulan Mei - Agustus 2018 di Kecamatan Sijunjung dan Kecamatan Sumpur Kudus, Kabupaten Sijunjung, Data yang diguankan terdiri dari data primer dan sekunder. Data primer diperoleh melalui observasi langsung ke lokasi dan wawancara dengan instansi terkait di Kabupaten Sijunjung yakni Dinas Pariwisata, Pemuda dan Olah Raga, Bappeda Kabupaten Sijunjung serta Wali Nagari Silokek. Sedangkan data sekunder bersumber dari penelusuran literatur 
melalui dokumen teknis, jurnal dan artikel ilmiah terkait lainnya. Data dianalisis secara deskriptif kualitatif. yakni membandingkan dengan kriteria UNESCO Global Geopark (UNESCO, 2006 dalam Setyadi, DA., 2012) yang mencakup 6 (enam) aspek yakni :

a. Ukuran dan Parameter

Memiliki batas yang jelas dan luas untuk dapat mencakup aktivitas pengembangan budaya dan ekonomi lokal. Selain itu juga harus terdapat sejumlah situs warisan geologi yang penting dan berskala internasional, yang langka dan memiliki nilai ilmiah, serta keindahan. Selain bersifat geoheritage, unsur non-geologi atau warisan lainnya juga terintegrasi sebagai bagian dari geopark.

b. Manajemen Pengelolaan

Adanya badan/institusi yang berfungsi sebagai manajemen pengelola dengan rencana pembangunan yang komprehensif. Manajemen umumnya berbentuk komite koordinasi yang bertindak untuk mempertemukan para pemangku kepentingan utama yang bertanggung jawab untuk pengembangan sektor masing-masing, Salah satu faktor kunci keberhasilan dalam inisiatif untuk membuat geopark adalah keterlibatan pemerintah lokal dan masyarakat dengan komitmen dukungan yang kuat dari pemerintah pusat.

c. Pengembangan Ekonomi

Salah satu tujuan strategis utama dari pembentukan geopark adalah peningkatan ekonomi dan mempromosikan pembangunan berkelanjutan. Geopark menstimulasi usaha lokal yang inovatif, pusat bisnis skala kecil, industri rumahan dan kursus pelatihan yang berkualitas dan pembukaan lapangan pekerjaan baru untuk mendukung pembangunan sosialekonomi lokal, khususnya melalui kegiatan geotourisme.

d. Aspek Pendidikan

Geopark harus menyediakan dan mendukung peralatan dan kegiatan untuk pengembangan ilmu pengetahuan, terutama pengetahuan geoscience dan konsep perlindungan lingkungan kepada publik. Beberapa infrastruktur dasar, seperti pusat informasi, museum sejarah dan pengetahuan alam, dan pengembangan rute geotrack untuk kepentingan studi lapangan sangat penting untuk mendukung pendidikan publik. 
e. Aspek Konservasi dan Perlindungan

Geopark adalah sarana pengembangan dimana konservasi kawasan lindung yang ada dapat diperkuat dan pada saat yang sama kesempatan untuk pembangunan sosial ekonomi masyarakat lokal dapat lebih ditingkatkan secara simultan. Otoritas pengelola kawasan geopark bertanggung jawab untuk memastikan bahwa perlindungan dari warisan geologi dilaksanakan sesuai dengan nilai-nilai tradisi lokal dan sesuai dengan ketentuan peraturan yang berlaku.

f. Kerjasama Jaringan Global

Untuk memperkuat jaringan dan berkontribusi terhadap peningkatan kualitas geopark maka geopark nasional harus masuk dalam kerjasama jaringan global yakni sebagai anggota Global Geoparks Network (GGN) sehingga terjadi pertukaran para ahli dan praktisi dalam bidang warisan geologi dan situs- situs geologi dapat memperoleh pengakuan di seluruh dunia.

\section{HASIL DAN PEMBAHASAN}

\section{Gambaran Umum Lokasi Kajian}

Kawasan Geopark Silokek terletak di Kecamatan Sijunjung dan Kecamatan Sumpur Kudus, Kabupaten Sijunjung. Kawasan ini meliputi 20 nagari dengan luas kawasan $\pm 1300 \mathrm{~km}^{2}$ dan jumlah penduduk 68.000 jiwa. Silokek terletak di bagian Timur dari Kota Padang dan merupakan bagian dari perbatasan antara Sawahlunto dan Kabupaten Solok Lebih tepatnya terletak pada titik koordinat 00³7'58,9"S (Lintang Selatan) / 10059'47.3"E (Bujur Timur). Silokek berjarak lebih kurang 15 kilometer dari Ibukota Kabupaten Sijunjung yakni kota Muaro Sijunjung dan berjarak $145 \mathrm{~km}$ dari Kota Padang dengan jarak tempuh selama 4 jam perjalanan. 


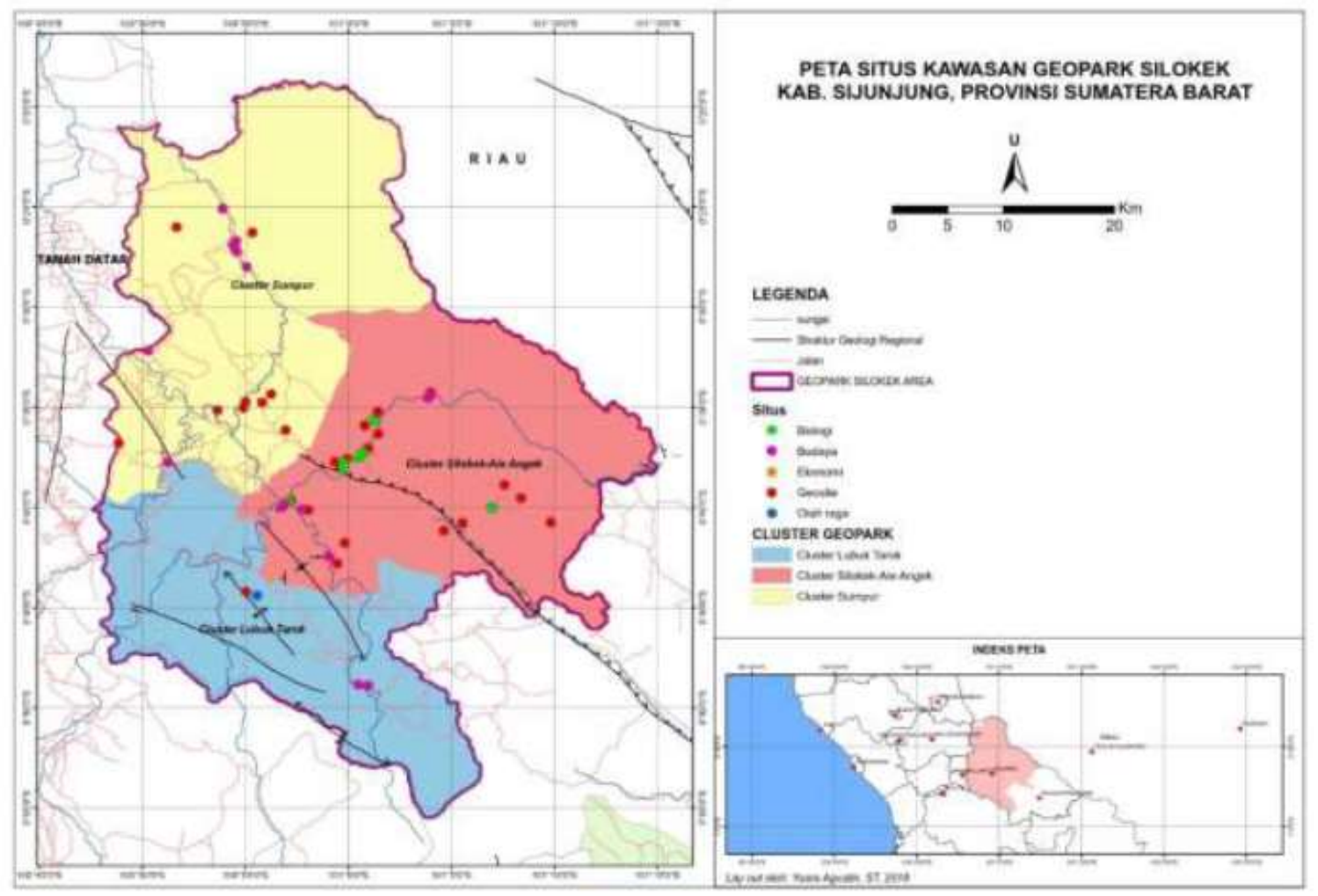

Gambar 1. Peta Situs Kawasan Geopark Silokek Sijunjung Sumber : Dossier Silokek, 2018

Situs-Situs yang Terdapat Dalam

\section{Kawasan Geopark Silokek}

Situs-situs geologi di Kawasan Geopark Silokek telah memperoleh perlindungan tingkat nasional melalui SK Menteri Lingkungan Hidup dan Kehutanan Nomor:

SK.603/Menlhk/Setjen/PLA.2/8/2016 tentang Penetapan Fungsi Pokok Kawasan Suaka Alam Kawasan Pelestarian Alam Sebagai Taman Wisata Alam Batang Pangian I di Kabupaten Sawahlunto Sijunjung Provinsi Sumatera
Barat yang menetapkan kawasan tersebut menjadi kawasan konservasi seluas lebih 14.288 Ha. Pada tingkat Kabupaten untuk perlindungan kawasan Geopark Silokek dikukuhkan melalui Peraturan Kabupaten Sijunjung No. 5 Tahun 2012 tentang Rencana Tata Ruang Kabupaten Wilayah Sijunjung Tahun 2011 - 2031.

Proses identifikasi terhadap situssitus yang ada di dalam Geopark Silokek sudah selesai dilakukan. Hardian, D (2018) telah mengidentifikasi 25 situs geodiversity (keragaman geologi) yang 
terdiri dari goa/ngalau, air terjun, bukit karst, pemandian air panas, pasir putih, dan lain-lain. Situs-situs ini terbagi dalam 3 (tiga) kluster yakni Silokek (3 situs), Sumpur Kudus (11 situs) dan Paru - Aie

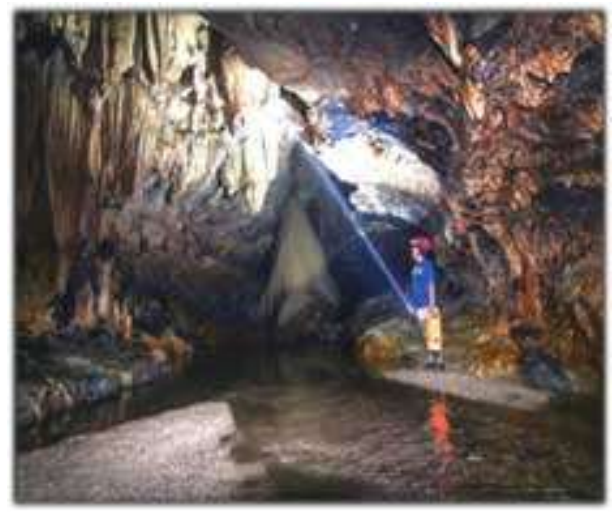

Gambar 2. Ngalau/Goa Basurek

Kekayaan flora dan fauna yang terdapat di Kabupaten Sijunjung diperkirakan lebih kurang 45.000 jenis. Potensi tersebut banyak terdapat di Nagari Paru. Nagari Paru pernah mendapat Kalpataru pada Tahun 2014 karena manajemen hutan yang dikelola berbasis nagari. Beberapa flora dan fauna langka dan dilindungi antara lain : bunga berdaun satu (monophyllaea) dan bunga bangkai (amorphophallus titanium), Harimau Sumatera (Panthera tigris sumatrae), Tanuk/Tapir (Tapirus indicus), Trenggiling (Manis javanica), Burung Enggang/Rangkong (Buceros
Angek (6 situs). Situs geodiversity tersebut merupakan batuan tua yang berumur 359 juta tahun yang terdiri dari batuan gamping (karst), batuan sedimen, batuan metamorf dan intrusi granit.

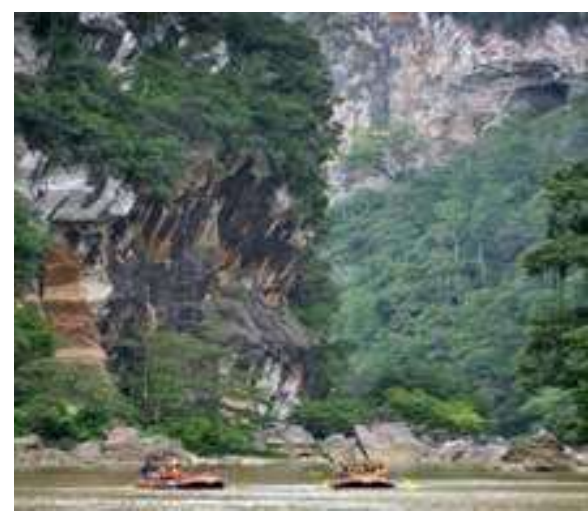

Gambar 3. Bukit Karst

vigil). Situs biodiversity (keragaman biologi) teridentifikasi sebanyak 12 situs antara lain : Taman Bunga Bangkai, Taman flora fauna malam, Taman Bunga Unik Silokek, Mini Zoo, Taman ikan jinak, Mini Zoo, dan lain-lain. Sedangkan situs cultural diversity, teridentifikasi sebanyak 17 situs yang terdiri dari : lokomotif uap Jepang, perkampungan adat, batu angkek angkek, Wisata Religius Calau, dan lain-lain (Dossier Siolek, 2018). Beberapa gambar situs bidodiversity dan cultural diversity dapat dilihat pada Gambar 4-7 berikut. 


\section{Situs Biodiversity}

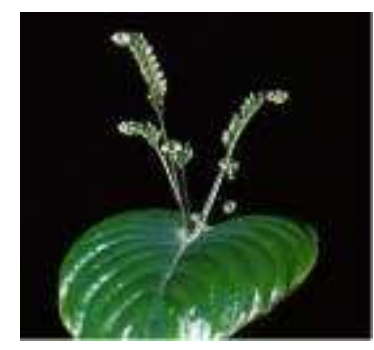

Gambar 4. Bunga Unik (berdaun Satu)

Situs Cultural Diversity

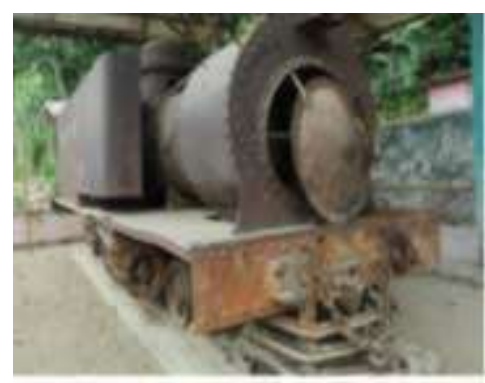

Gambar 6. Lomotif Uap Peninggalan Jepang

Analisis Kondisi Geopark Silokek terhadap Kriteria UGG

Ukuran dan parameter

Kriteria ini sudah terpenuhi karena luas Kawasan Geopark Silokek cukup besar yakni $\pm 1.300 \mathrm{~km}^{2}$ yang meliputi 2 (kecamatan) yakni Sijunjung dan Sumpur Kudus. Sebagai perbandingan, Geopark Ciletuh Pelabuhan Ratu di Jawa Barat yang sudah mejadi global geopark mememiliki luas $1.261 \mathrm{~km}^{2}$. Di dalam Kawasan Geopark Silokek terdapat situs-situs warisan geologi yang penting dan berskala internasional, langka dan memiliki nilai

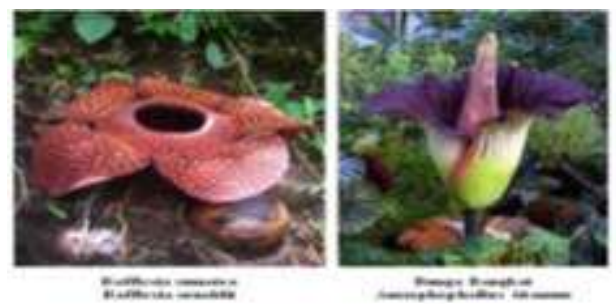

Gambar 5. Bunga Bangkai dan Rafflesia

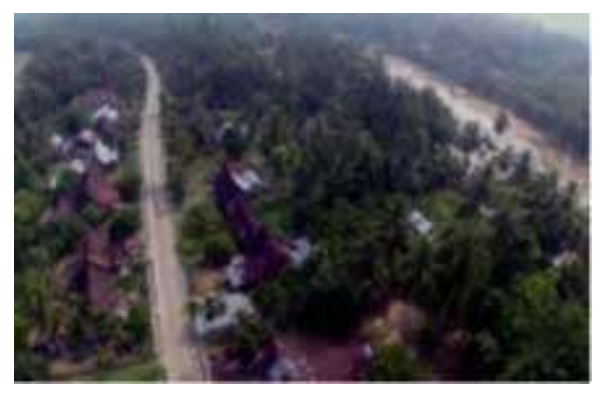

Gambar 7. Perkampungan Adat ilmiah seperti goa, air terjun, bukit karst. Disamping itu terdapat situs non geologi berupa flora dan fauna langka serta warian budaya yang masih terjaga dengan baik.

Manajemen Pengelolaan

Badan Pengelola Geopark Silokek dibentuk berdasarkan Surat Keputusan Bupati Sijunjung Nomor : 188.45/404/KPTS-BPT-2018 tanggal 20 September 2018. Unsur-unsur yang ada dalam struktur organisasi Badan Pengelola adalah Pembina, Ketua Umum, Wakil Ketua I, Wakil Ketua II, Wakil Ketua III, Tim Ahli, Sekretariat dan 
Divisi-Divisi (Gambar 8). Jika dianalisis, struktur Badan Pegelola Geopark Silokek ini tidak efektif dan efisien. Terdapat divisi yang sebenarnya dapat digabung untuk pelaksanaan tugasnya yakni divisi pariwisata dengan divisi promosi dan event. Disamping itu, Sekretariat sebaiknya tidak berada sejajar dengan divisi-divisi karena tugasnya yang berbeda sebagaimana struktur Badan
Pengelola Geopark Rinjani (Gambar 9). Hal lain adalah jumlah wakil ketua yang juga terlalu banyak untuk mengkoordinir masing-masing divisi. Sebagai perbandingan, Gambar 10 menunjukkan struktur Badan Pengelola Cagar Alam Geologi Karangsembung yang diadaptasi dari model Langkawi Global Geopark, Malaysia.

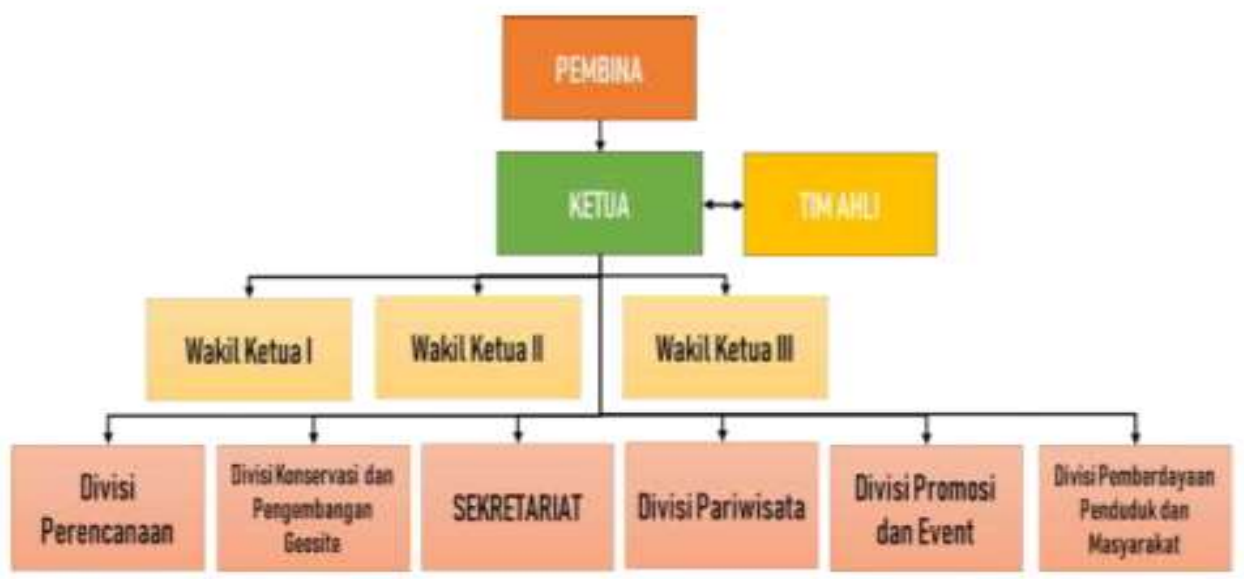

Gambar 8.Struktur Organisasi Badan Pengelola Geopark Silokek Sumber : Dosier Silokek, 2018 


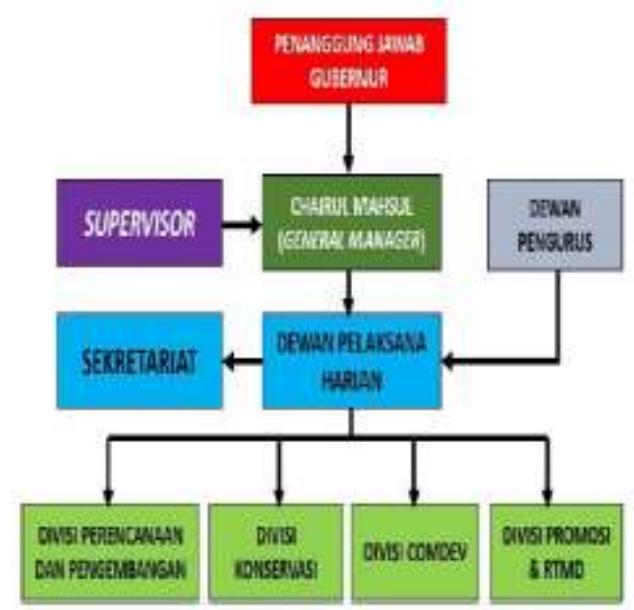

Gambar 9. Struktur Badan Pengelola Geopark Rinjani Lombok Sumber : Rachmat, $H$

Berdasarkan hasil analisis struktur badan pengelola geopark tersebut di atas maka diusulkan untuk mengembangkan struktur

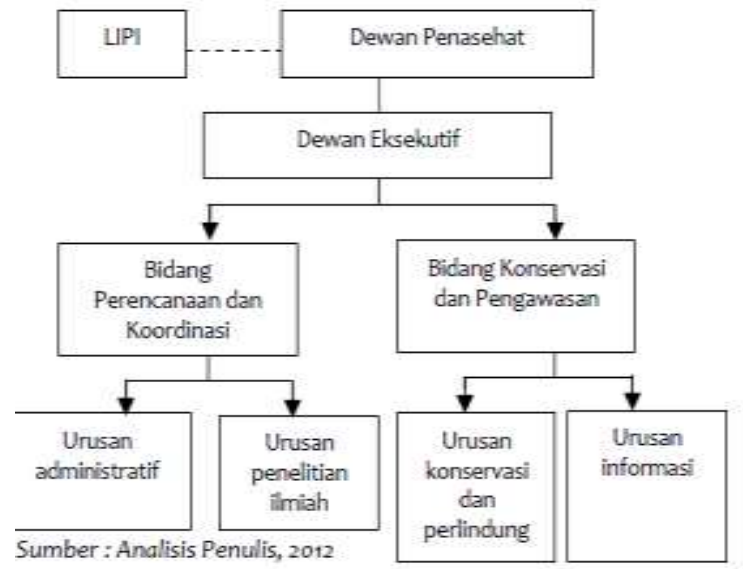

Gambar 10. Struktur Badan Pengelola Cagar Alam Geologi Karang Sembung Berdasarkan Adaptasi Model Geopark Langkawi, Malaysia Sumber : Syahrijati, PSA., 2018

Badan Pengelola Geopark yang lebih efektif dan efisien sebagaimana Gambar 11 berikut.

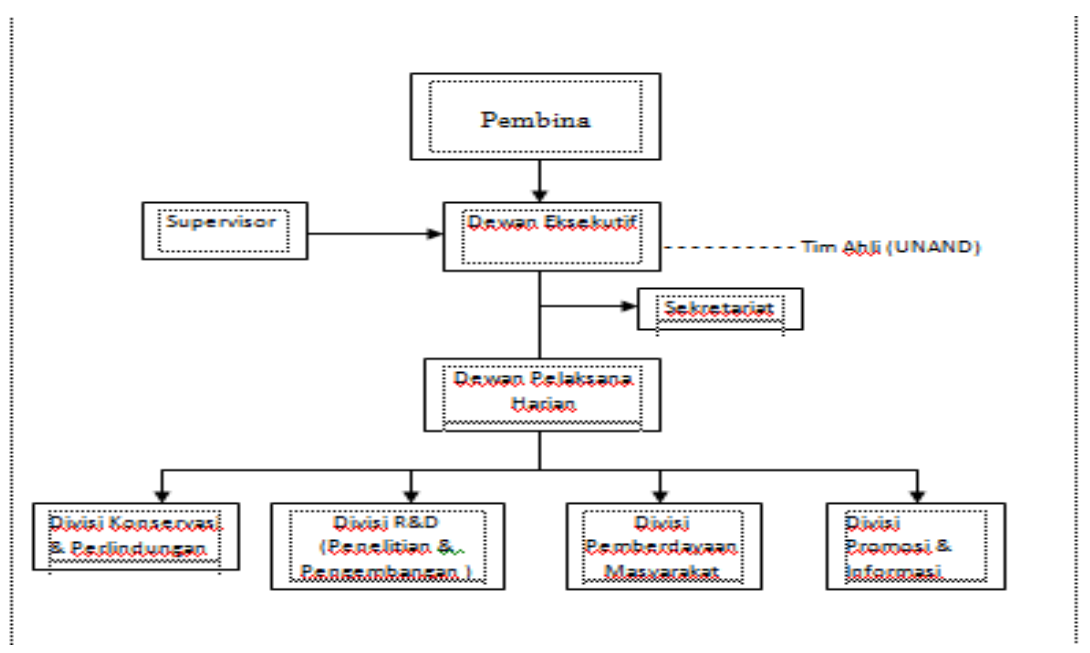

Gambar 11. Struktur Badan Pengelola Geopark Silokek hasil modifikasi Sumber : Hasil analisis, 2018

\section{Pengembangan Ekonomi}

Produk Domestik Regional Bruto

(PDRB) Atas Dasar Harga Berlaku

menurut Lapangan Usaha Kabupaten
Sijunjung pada Tahun 2017 mencapai 7,98 Trilyun Rupiah dengan pertumbuhan ekonomi sebesar 5,27\%. didominasi oleh 4 (empat) sektor yakni pertanian, 
kehutanan dan perikanan (30,71\%), pertambangan dan penggalian $(14,02 \%)$, konstruksi $(13,06 \%)$ serta perdagangan besar dan eceran, reparasi mobil dan motor sebesar 11,49\% (BPS Kabupaten Sijunjung, 2018). Berdasarkan data tersebut dapat dilihat bahwa sektor pertanian, kehutanan dan perikanan merupakan mata pencaharian terbesar dengan komoditi utama karet, kelapa sawit dan padi sawah. Sedangkan pertambangan dan galian menempati urutan kedua mata pencaharian masyarakat di Kabupaten Sijunjung dan salah satu potensi tambang yang cukup besar adalah emas.

Jika dilihat dari perkembangan PDRB Kabupaten Sijunjung dari tahun 2010 - 2017, terjadi penurunan pertumbuhan ekonomi selama 5 (lima) tahun terakhir (Gambar 12). Pertumbuhan ekonomi ini dapat dipacu lagi dengan memaksimalkan potensi sektor pariwisata karena Kabupaten Sijunjung memiliki sumberdaya alam yang indah dan menarik melalui pengembangan Kawasan Geopark Silokek (Balitbang Sumbar, 2018).

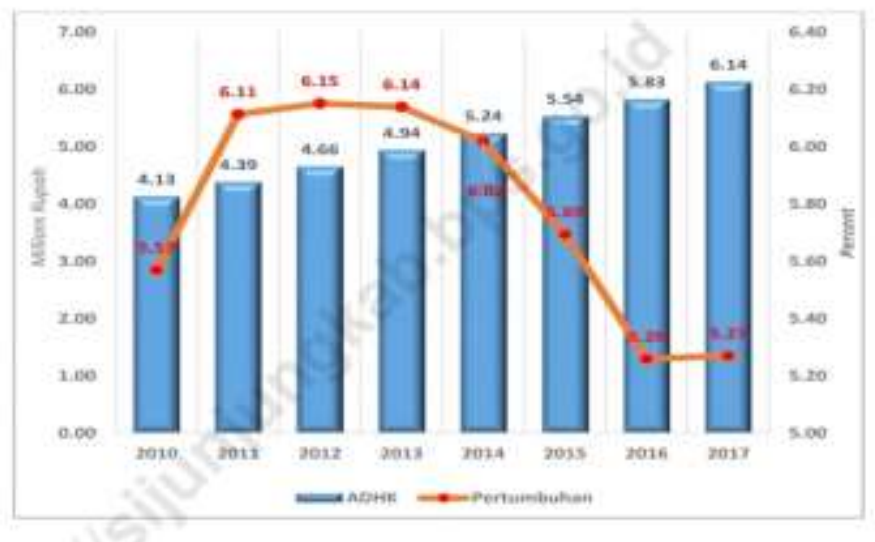

Gambar 12. PDRB Atas Dasar Harga Berlaku Menurut Lapangan Usaha di Kabupaten Sijunjung Tahun 2010 - 2017

Sumber : BPS Kabupaten Sijunjung, 2018

Jika dilihat dari pengalaman Batur Global Geopark. Syahrijati, PSA, 2018 mengemukakan bahwa sejak ditetapkannya Batur sebagai Global Geopark, tidak terjadi perubahan standar hidup masyarakat lokal. Kondisi ini disebabkan karena masyarakat tidak dilibatkan dalam kegiatan yang direncanakan oleh pemerintah setempat sehingga masyarakat merasa bahwa 
mereka tidak diharapkan untuk terlibat dan mereka tidak penting untuk terlibat.

Agar masyarakat dapat terlibat sehingga ekonomi masyarakat di Kawasan Geopark Silokek dapat berkembang maka perlu dilaukan upayaupaya sebagaimana yang direkomendasikan S. Sagala (2018) pada Geoaprk Batur antara lain : (i) melaksanakan seminar dan training yang dikerjasamakan dengan perguruan tinggi setempat, lembaga penelitian dan asosiasi seperti PHRI untuk memberikan keterampilan wirausaha pada masyarakat lokal, (ii) membentuk badan/institusi pengelola geopark secara khusus, (iii) membuat peraturan khusus untuk mengatur perekonomian lokal termasuk strategi promosi dan pemasaran produk lokal, (iv) membuat panduan untuk melatih masyarakat sehingga selain dapat menjaga geopark, juga dapat menjadi guide, membuat produk dan atraksi lainnya, (v) menciptakan perencanaan parisipatif melibatkan masyarakat lokal, (vi) menyusun regulasi untuk menguatkan koorsinasi pemerintah pusat, provinsi dan kabupaten/kota, (vii) sinkronisasi perencanaan Geopark Silokek dengan dokumen perencanaan pemerintah seperti
Rencana Tata Ruang Wilayah (RTRW) dan Detail RTRW.

Aspek Pendidikan

Berdasarkan hasil Musyawarah Rencana Pembangunan (Musrenbang) Kabupaten Sijunjung Tahun 2019, beberapa instansi pemerintah telah mengalokasikan anggaran dan kegiatan untuk mendukung pengembangan Geopark Silokek diantaranya Dinas Pendikan dengan membuat kegiatan Geopark Silokek to School dan One Day with Geopark Silokek. Syahrijati, PSA (2018) mengemukakan bahwa pada aspek pendidikan ini penting untuk memperdalam pengetahuan tentang ilmu bumi melalui kunjungan lapangan dan pameran atau festival biologi.

Kegiatan lain yang perlu untuk menunjang aspek pendidikan pada geopark adalah pembangunan geotrack sebagai jalur multifungsi untuk penelitian dan pariwisata danuntuk memudahkan aktifitas penduduk di sekitar kawasan. Jalur geotrack juga menghubungkan antar situs, desa, museum dan pusat-pusat kerajinan. Di sepanjang jalur geotrack harus diberi panel interaktif dan informatif seperti panel penunjuk jalan dan penunjuk posisi saat ini, panel 
informasi fasilitas di tiap-tiap rute tujuan seperti galeri, tempat istirahat, pusat kerajinan, restoran, supermarket, toilet umum dan mushalla/mesjid.

Untuk Geopark Silokek, ke depannya geotrack dapat dibuat 3 (tiga) jalur sesuai dengan kluster yang ada yakni kluster Silokek, Sumpur Kudus dan Paru-Aie Angek. Terkait dengan fasilitas untuk menunjang jalur geotrack, di daerah Silokek saat ini baru terdapat 1 (satu) toilet umum dan 1 (satu) mushalla dengan fasilitas seadanya.

Aspek Konservasi dan Perlindungan

Kriteria aspek konservasi dan perlindungan sudah dipenuhi oleh Geopark Silokek dengan ditetapkannya kawasan konservasi seluas lebih 14.288 Ha melalui SK Menteri Lingkungan Hidup dan Kehutanan Nomor: SK.603/Menlhk/Setjen/PLA.2/8/2016 tentang Penetapan Fungsi Pokok Kawasan Suaka Alam Kawasan Pelestarian Alam Sebagai Taman Wisata Alam Batang Pangian I di Kabupaten Sawahlunto Sijunjung Provinsi Sumatera Barat.

Kerjasama Jaringan Global Apabila semua kriteria yang sudah diuraikan di atas sudah dipenuhi oleh Geopark Silokek maka langkah selanjutnya adalah segera mendaftar dalam kerjasama jaringan global dibawah Asia Pasific Geoparks Network/APGN) dan geopark interasional (Global Geopark Network/GGN).

\section{Pemberdayaan Masyarakat}

Kegiatan pemberdayaan masyarakat merupakan hal yang penting dalam geopark, dimana masyarakat diberi berbagai macam pelatihan seperti : Pelatihan pemandu wisata, pelatihan pengolahan produk makanan berbahan lokal, pelatihan pengetahuan tentang geopark, pengelolaan lingkungan, pelatihan penanganan keadaan darurat kecelakaan, termasuk di dalamnya pembinaan membuat dan mengelola homestay, rumah makan atau kuliner, kerajinan tangan serta cendera mata (Dinas Pariwisata dan Kebudayaan Jawa Barat, 2017).

Syahrijati, PSA. (2018) menyatakan bahwa pengelola geopark juga harus melakukan pertemuan dengan masyarakat setempat, membahas perencanaan dan pengembangan program pemberdayaan masyarakat sebagai pemandu wisata, pengelola dan staf di agen-agen penginapan maupun restoran lokal dan 
penjual barang-barang kerajinan di galeri seni. Disamping itu, masyarakat juga harus dilatih tentang kemampuan bahasa, teknologi komunikasi, manajemen pemasaran, kreativitas, inovasi dan pengembangan kerajinan yang dilakukan di kelas-kelas pelatihan dan praktek di lapangan.

Untuk peningkatan kapasitas masyarakat di Kawasan Geopark Silokek, Tim BCA Pusat telah melakukan pembinaan dan pendampingan pada masyarakat melalui pelatihan service excellent dalam menyambut/mendampingi wisatawan yang akan berkunjung ke Geopark Silokek. Pada Tahun 2018, telah dilakukan 2 (dua) kali pelatihan yakni kepada masyarakat di Perkampungan adat dan kepada Kelompok Sadar Wisata (Pokdarwis) Pasir Putih Silokek. Selanjutnya pada Bulan Januari-Februari 2019 telah dilakukan pelatihan pemandu wisata di Nagari Silokek dan pelatihan pengelola homestay di Perkampungan Adat.

Tantangan Pengelolaan Lingkungan dalam Pengembangan Geopark
Silokek : Pencemaran Sungai Batang Kuantan

Sungai Batang Kuantan merupakan sungai stategis nasional lintas provinsi, hulunya berada di Provinsi Sumatera Barat dan hilirnya berada Provinsi Riau. Untuk segmen Sumatera Barat, baik hulu sungai maupun hilir berada di Kabupaten Sijunjung, hulu berada pada Kecamatan Sijunjung dan hilir pada Kecamatan Kamang Baru. Hulu sungai merupakan pertemuan 2 sungai, yakni Batang Ombilin dan Batang Palangki di Kabupaten Sijunjung

Dari hasil pengamatan di daerah Silokek, terlihat air Sungai Batang Kuantan keruh dan berwarna kuning kecoklatan sebagaimana dapat dilihat pada Gambar 13 Kondisi air Sungai Batang Kuantan tersebut diakibatkan oleh adanya kegiatan penambangan emas (baik legal maupun illegal) serta penambangan galian C (pasir, batu, kerikil) yang dilakukan pada anak sungai Batang Kuantan yakni Batang Palangki yang terletak antara Kabupaten Sijunjung dan Kabupaten Solok. 

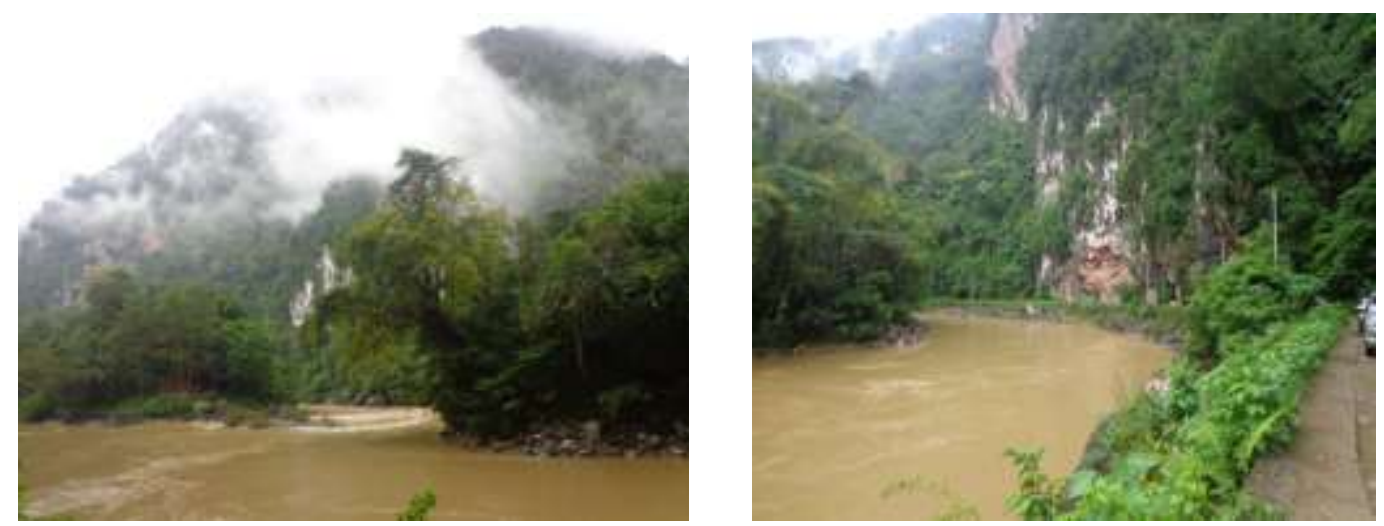

Gambar 13. Aliran Sungai Batang Kuantan di Kawasan Silokek Sumber : Dokumentasi lapangan, 2018

Untuk mengatasi permasalahan pencemaran Sungai Batang Kuantan tersebut, telah dirumuskan 4 (empat) strategi yakni :pemantauan yang kontinu Sungai Batang Kuantan dan anak sungainya oleh Dinas Lingkungan Hidup Provinsi Sumatera Barat serta Dinas Lingkungan Hidup dan Pemukiman Wilayah Kabupaten Sijunjung, memanfaatkan dukungan Pokdarwis untuk menjaga dan mengelola lingkungan sungai, menciptakan lapangan kerja baru dari sektor pariwisata Geopark Silokek (pemandu wisata geopark, pemandu arung jeram, Kerajinan/UKM berupa souvenir dan lain-lain) dan membentuk Sekretariat Bersama antara Pemerintah Kabuapten Sijunjung dan Pemerintah Kabupaten Solok untuk menyusun program/kegiatan mengurangi penambangan emas tanpa izin di Batang
Palangki yang merupakan anak Sunagi Batang Kuantan (Kusuma, D.W., 2018).

\section{KESIMPULAN}

Untuk dapat mendaftarkan Geopark Silokek di UNESCO Global Geopark (UGG) terdapat beberapa kriteria yang harus disempurnakan/diperbaiki yakni struktur badan pengelola geopark, aspek pengembangan ekonomi dan aspek pendidikan. Selain kriteria dari UNESCO, masalah pencemaran Sungai Batang Kuantan yang dilalui oleh Kawasan Geoaprk Silokek juga harus segera diselesaikan.

\section{REKOMENDASI}

Merevisi Badan Pengelola Geopark Silokek, membangun jalur geotrack beserta fasilitas pendukungnya, meningkatkan pemberdayaan masyarakat dan mengatasi permasalahan lingkungan pada Sungai Batang Kuantan. 
Selanjutnya bergabung dengan jaringan geopark regional (Asia Pasific Geoparks

\section{DAFTAR PUSTAKA}

Badan Pusat Statistik. 2018. Kabupaten Sijunjung dalam Angka.

Balitbang Provinsi Sumatera Barat. 2018. Pengembangan Kawasan Geopark Sumatera Barat dalam Kegiatan Survey Pemetaan dan Perumusan Kebijakan Strategis Tahun 2018. Laporan Akhir Penelitian.

Dinas Pariwisata, Pemuda dan Olah Raga

Kabupaten Sijunjung. 2017.

Laporan Kinerja Instansi

Pemerintah.

Dinas Pariwisata dan Kebudayaan Provinsi Jawa Barat. 2017. Geopark Ciletuh Pelabuhan Ratu.

Ismail, F.A., Meideliza, T., Hardian, D., 2018. Kajian Potensi Geopark Silokek. Bahan paparan pada Seminar Hasil Kajian Pengembangan Geopark di Kabupaten Sijunjung Sumatera Barat tanggal 12 Oktober 2018 di Balitbang Prov. Sumbar.

Kusuma, D.W, 2018. Strategi Pengendalian Pencemaran Sungai Batang Kuantan dalam Upaya Mendukung Kawasan Geopark di Kabupaten Sijunjung. Prosiding Seminar Nasional Pelesatrian Lingkungan. LPPM Universitas Riau.

Pemerintah Kabupaten Sijunjung. 2018. Geopark Silokek- Sijunjung Sumatera Barat : Dokumen Pengusulan Menjadi Geopark Nasional dan Keanggotaan pada Jaringan Geopark Nasional Indonesia (Dossier Silokek).

Rachmat, H., Peran Pemerintah Daerah Untuk Mendukung Geopark
Network/APGN) dan geopark interasional

(Global Geopark Network/GGN).

Nasional Rinjani menjadi Rinjadi UNESCO Global Geopark. Seminar Nasional ke III Fakultas Teknik Geologi Universitas Padjajaran.

S. Sagala et al. 2018. Who Gets Benefit of Geopark Esstablisment. A Study of Batur Geopark Area, Bali Province Indonesia. IOP Conference Series: Earth and Environmental Science. Volume 158.conference1.

Syahrijati, PSA., 2018. Kontribusi Batur Global Geopark dalam

Perekonomian Lokal di Kintamani. JUMPA, Volume 4 Nomor 2, Januari 2018.

Setyadi, D.A., 2012. Studi Komparasi Pengelolaan Geopark Dunia untuk Pengembangan Pengelolaan Kawasan Cagar Alam Geologi Karangsambung. Jurnal Pembangunan Wilayah dan Kota. Volume 8 No. 4. Desember 2012. Palanologi Universitas Diponegoro Semarang.

Tim Geopark Ranah Minang. 2018. Mewujudkan Geopark Ranah Minang : Usulan Masyarakat untuk Mewujudkan Geopark di Sumatera Barat. Booklet Geopark Ranah Minang.

Wibowo, Y.G., Zahar, W., dkk., 2019. Pengembangan Eco-Geotourism Geopark Merangin Jambi. Indonesian Journal of Environmental Education and Management (IJEEM). Volume 4 No.1. Januari 2019. 